\title{
Living and Working in a Multisensory World: From Basic Neuroscience to the Hospital
}

\author{
Kendall Burdick ${ }^{1}$ (), Madison Courtney ${ }^{2}$, Mark T. Wallace ${ }^{3}$, Sarah H. Baum Miller ${ }^{4}$ and \\ Joseph J. Schlesinger $5, * \mathbb{D}$, \\ 1 Department of Neuroscience, Vanderbilt University, 1211 21st Avenue South, Medical Arts Building, \\ Suite 422, Nashville, TN 37212, USA; kendall.burdick@vanderbilt.edu \\ 2 Department of Medicine, Health and Society, Vanderbilt University, 1211 21st Avenue South, \\ Medical Arts Building, Suite 422, Nashville, TN 37212, USA; madison.c.courtney@vanderbilt.edu \\ 3 Department of Neuroscience, Vanderbilt University, 465 21st Avenue South, Nashville, TN 37232, USA; \\ mark.wallace@vanderbilt.edu \\ 4 Department of Psychology, University of Washington, Main Office Mailbox 357270, T-471 Health Sciences \\ Center, Seattle, WA 98195, USA; sarah.baummiller@gmail.com \\ 5 Department of Anesthesiology, Division of Critical Care Medicine, Vanderbilt University Medical Center, \\ 1211 21st Avenue South, Medical Arts Building, Suite 422, Nashville, TN 37212, USA \\ * Correspondence: joseph.j.schlesinger@vanderbilt.edu; Tel.: +1-(615)-727-4880
}

Received: 29 November 2018; Accepted: 31 December 2018; Published: 8 January 2019

check for updates

\begin{abstract}
The intensive care unit (ICU) of a hospital is an environment subjected to ceaseless noise. Patient alarms contribute to the saturated auditory environment and often overwhelm healthcare providers with constant and false alarms. This may lead to alarm fatigue and prevent optimum patient care. In response, a multisensory alarm system developed with consideration for human neuroscience and basic music theory is proposed as a potential solution. The integration of auditory, visual, and other sensory output within an alarm system can be used to convey more meaningful clinical information about patient vital signs in the ICU and operating room to ultimately improve patient outcomes.
\end{abstract}

Keywords: music perception; alarm fatigue; intensive care unit; auditory icons

\section{Introduction}

While engaging in dinner conversation in an elegant restaurant, your attention is simultaneously tuned to the television screen overhead, the siren and flashing lights of a passing ambulance, the radio song playing in the background, and the gossip at the table next to you. Your attention is both voluntarily and involuntarily divided among these competing stimuli. You are certainly not affording your dinner companion your undivided attention. This is one example of the multisensory world in which we live and highlights the dynamic interactions that are continually taking place across the various sensory systems [1]. For the purpose of this article, we will use the term multisensory to refer to stimuli that are contextually similar and are aligned temporally and spatially as found in nature [2]. Multisensory alarms consist of interactions between multiple sensory streams, not just multiple concomitant unisensory streams. Indeed, one of the major challenges for our brains is to decide what amongst this vast array of sensory information to filter out and what should gain preferential access to be processed further.

For the clinician, a prime example of a complex multisensory environment is the intensive care unit (ICU), where they must respond to a myriad of changes in an environment filled with a complex mélange of sensory information from patient monitors, alarms, speech, and other salient stimuli. In a typical ICU, there may be as many as 700 alarms per patient per day [3]. The relevant data 
must be discerned, assimilated, and decided upon while irrelevant data needs to be filtered and disregarded, a challenge made more difficult when attentional demands exceed individual capacity [4]. From a patient point of view, such alarms can be troubling and disruptive to healing, yet they are often dismissed by clinicians, possibly contributing to further patient anxiety [5]. Beyond medicine, alarms have the potential to be problematic in the aviation and automotive industries [6-8].

Even within the sense of audition alone, evidence suggests that the quantity of information and the levels of stimulation can overwhelm the clinician, creating the potential for adverse effects and outcomes. Research shows that both clinicians and patients in the ICU are subjected to noise levels that far exceed occupational ambient sound recommendations, furthered by excessive clinical alarms. The World Health Organization (WHO) recommends that noise levels should not exceed 30 decibels $(\mathrm{dB})$ at night in hospitals, yet these values are often recorded around $60 \mathrm{~dB}[9,10]$. Noise exposure can adversely affect the health and healing of ICU patients which can manifest as increased blood pressure, hemodynamic instability, loss of sleep, delayed wound healing, delirium, increased sedation requirements, and hyperglycemia [3,11]. In addition to negatively affecting patients, excessive noise in a work environment is associated with miscommunication, inattention, loss of concentration, memory impairment, headaches, burnout, fatigue, and impaired task performance of clinicians [3]. Most often, this saturated auditory environment leads to alarm fatigue- the desensitization to alarms-and to masking of relevant information by unnecessary noise, both of which are deleterious to the practitioner and the patient $[3,4,12-14]$.

The repercussion of maladaptive alarms is now being recognized by regulatory agencies. In 2013, The Joint Commission's (TJC) Sentinel Event database included reports of 98 alarm-related events between January 2009 and June 2012, of which 80 resulted in death, 13 in permanent loss of function, and five in additional care or extended stay [15]. Additionally, the U.S. Food and Drug Administration's (FDA) Manufacturer and User Facility Device Experience (MAUDE) database reveals that 566 alarm-related patient deaths were reported between January 2005 and June 2010 [16]. Both statistics are based on voluntary reporting, and should be considered gross underestimates of the true incidence of alarm-related patient harm.

In trying to combat disruptive noise, some clinicians decrease alarm volumes, but often reduce them to inaudible levels. The Emergency Care Research Institute (ECRI) specifically cites this as a major issue of alarm mismanagement, highlighting the need for better solutions to alarm noise [17]. TJC declared alarm management as a 2014 National Patient Safety Goal [16], and alarm improvement has also been a priority for the Association for the Advancement of Medical Instrumentation (AAMI). An outcome of the 2011 AAMI-FDA summit on alarms was the vision that "by 2017, no patient will be harmed by adverse alarm events" [18]. It is clear from these statements that further research on alarms is desperately needed in order to inform and guide individual and institutional alarm management.

\section{The Intersection of Music Perception and Cognition with Neuroscience to Improve Audible Medical Alarms}

The most prevalent alarms are founded on auditory stimulation, as it is readily perceived in the free field space of most clinical environments. However, the use of auditory alarms to communicate an abundance of patient information has resulted in a proliferation of noise. The interpretation of sound by the human brain involves neuroscience as a key factor in making improvements to future alarms systems.

Neuroscience-related research could add value to alarm design in the area of music cognition and perception. While present auditory alarms are not musical per se, the acoustic features of alarms can be better understood using concepts derived from music perception and cognition. Pitch differences in some pulse oximeters, a commonly used patient monitor, follow a logarithmic scale, and some infusion pumps and mechanical ventilator alarms utilize melodic resolution (e.g., from the dominant [V] to the tonic [I], " $G$ " $\rightarrow$ " $C$ ") [19-21]. Most natural sounds are complex and comprised of multiple frequencies, differing from the pure tones (i.e., single frequency) of many alarms. Furthermore, many current 
alarms use flat amplitude envelopes (e.g., non-natural sounds like the emergency broadcast system) that make it difficult to discriminate between paired physiologic changes and their associated melodic mnemonics [22]. Utilizing percussive amplitude envelopes has been shown to improve recall in a memory task associating tone sequences with arbitrary object pairings, as well as decrease perceived annoyance. These data suggest possible areas of intervention which may lead to alarms that are less aversive and easier to learn $[23,24]$.

The lack of integration of basic musical principals into auditory cues highlights a missed opportunity to improve learnability and effectiveness of alarms [21,25]. The current design of auditory alarms fails to take advantage of the fact that multiple modes of processing for complex sounds may improve clinicians' ability to perceive and respond to alarms [23]. Furthermore, these auditory signals must be considered within the realm of the multisensory environment in which they are presented, as information from other sensory systems can greatly shape the way the same auditory information is processed.

Sensory neuroscience research, particularly multisensory neuroscience research-which focuses on the interactions between the different sensory systems (e.g., hearing and vision)—provides an innovative and timely perspective on this issue. Decades of research have shown that combining information from multiple sensory systems can confer marked behavioral benefits, particularly in noisy environments like clinical settings [26-28]. Therefore, applying the findings of basic multisensory neuroscience research can provide important insights that may be of practical benefit in ameliorating issues that relate to stimulus complexity and noise in clinical work environments.

Neuroscience principles derived from multisensory research translate to the clinical medical environment and may be directed in an effort to improve clinical care and physician well-being. The intersections between sensory function and attention, and issues such as alarm fatigue, emotional responses to alarms, and improved patient safety outcomes also provide avenues for future development. A neuroscience-based perspective on multisensory integration and opportunities for more effective alarm design will give insight into the future of the ICU.

\section{A Primer on Multisensory Integration and Its Potential Clinical Applications}

A reliable and robust finding in multisensory neuroscience is that the combination of multiple pieces of information from the different senses (compared to information presented in a single sense) can result in striking behavioral and perceptual benefits in detection, localization, and discrimination [29-35]. Although initially studied almost exclusively in controlled laboratory settings, an increasing body of work is now examining these performance benefits in more ecologically relevant settings. One of the most fundamental observations in this regard is the multisensory-mediated benefits observed in speech comprehension under noisy circumstances [36,37]. It has been shown that the ability to see the mouth movements of a speaker in a noisy setting (e.g., a cocktail party) can confer up to an effective 15-decibel ( $\mathrm{dB}$ ) advantage in the listener's ability to understand the spoken signal [36]. This visually mediated gain in intelligibility highlights the natural ability of the different sensory systems to work synergistically, and reinforces the potential for utilizing multisensory approaches toward the design of better alarms. While the focus of this review is on the interactions between the visual and auditory senses (as these are typical conduits for alarm-related information), multisensory-mediated advantages have been seen across all sensory combinations, including interactions between taste, smell, and touch [28,38-40].

Foundational work in the multisensory field has identified a series of integrative "principles" that have a strong intuitive basis and reinforce the applied benefits brought by having information available in multiple senses [41]. The first two of these are the spatial and the temporal principles, which relate to the physical relationship of paired stimuli to one another [42-45]. The eye and ear intertwine auditory and visual energy to provide information about an audiovisual event, like a ball bouncing against the floor [46-48]. Multisensory circuits within the brain use this spatial and temporal proximity between the auditory and visual information to decide whether these pieces of information 
are likely to have come from the same source or event [26,49]. Such spatially and temporally coincident pairings generally result in substantial improvements in behavior and perception, suggesting that the brain uses this statistical information about stimuli in the world to decide what belongs together (i.e., should be "bound") and what should be segregated [50-52].

The third multisensory principle is called "inverse effectiveness," and refers to the fact that the greatest proportional gains in neural response, behavior, and perception are typically seen when the individual sensory components of the paired stimuli are weakly effective $[33,53]$. Imagine a dim light and a soft sound, each of which may be sufficiently weak on their own that you cannot perceive them. However, when these stimuli are paired, you are much more likely to detect their presence [35]. As the individual stimuli become increasingly effective, multisensory-mediated performance gains decline, an intuitive result given that these stimuli become much easier for the brain to register individually $[35,36,54]$.

Not surprisingly, multisensory interactions abound in the clinical setting. For example, during minimally invasive procedures surgeons depend on the visual input from the camera on the monitor, the sound of the harmonic scalpel, and the haptic feedback with respect to texture, shape, and consistency of the tissue [55]. Although such situations are ubiquitous, and physicians readily integrate information across the senses in order to improve their perception and performance, it must be emphasized that the nature of the incoming sensory information is usually not optimized for efficient integration of this information under such high-consequence circumstances. Collectively, the principles of multisensory integration provide a framework for predicting what will happen when stimuli from the different senses are paired, and can (and should) be used as a starting point to create more effective parameters for presenting sensory information in clinical environments. Consider the principle of inverse effectiveness in the context of alarms. Popular thought suggests that an alarm/alert must be louder or brighter to be optimally effective $[56,57]$. Contrary to this, the pairing of weaker stimuli may be as effective in driving behavior, and most importantly could dramatically reduce many of the negative attributes (e.g., fatigue, stress) associated with very loud or bright stimuli $[3,34,58]$. Based on such examples, we advocate that knowledge and application of findings from multisensory research have the potential to greatly aid in the design and implementation of safer and more comfortable clinician workplaces $[4,14]$.

\section{An Investigation of the Utility of Applying Multisensory Principles in a Clinical Setting}

Research that has applied multisensory principles to the clinical setting has provided promising evidence for the ability to improve alarm design in the ICU. As highlighted earlier, time is an important dimension for multisensory integration, in that auditory and visual events that happen in close temporal proximity have a higher likelihood of being actively integrated and bound. The construct of a temporal binding window (TBW) has been proposed to characterize the temporal interval within which paired stimuli (for example, an audiovisual signal) are likely to be actively bound into a single perceptual construct [59-61]. Prior laboratory studies have shown that the TBW is malleable and can be narrowed with training, giving rise to improved multisensory temporal acuity [60]. Given this evidence for marked adaptability (i.e., plasticity) in multisensory temporal function, it was hypothesized that using this approach in a clinically oriented study could narrow an individual's TBW, and furthermore, improve audiovisual processing. By this logic, improving multisensory (audiovisual) temporal acuity would effectively amplify the binding of appropriate visual and auditory information, particularly during high attentional load conditions that mimic many normal clinical scenarios.

A study conducted by Schlesinger et. al. in 2014 examined the ability of anesthesiology residents to detect changes in the auditory signals delivered by a standard pulse oximeter before and after multisensory perceptual training. The cognitive demand of the ICU was replicated in the form of a rapid serial visual presentation (RSVP) task. Before training and under high attentional demand conditions, residents' ability to detect changes in oxygen saturation (signaled through unisensory pitch change) was significantly impaired. The addition of background auditory noise further degraded their 
performance. However, clinical accuracy and speed of response were improved by just two hours of multisensory perceptual training over a two-day period $[4,14]$.

This is a clear demonstration that a brief period of multisensory perceptual training can enhance clinicians' response to clinically meaningful signals in a high attentional and sensory demand environment similar to the ICU or operating room (OR). Despite this evidence, there is no form of multisensory perceptual training currently included in the education of physicians or nurses who perform physiological monitoring.

\section{Employing the Conceptual Framework of Inverse Effectiveness to the Operating Room}

The prior example of improving pulse oximetry detection through multisensory perceptual training highlights the use of temporal structure and temporally-based multisensory training as a tool to make better use of auditory information in the clinical setting. In a similar fashion, the principle of inverse effectiveness, described in the multisensory primer above, can be brought to bear on these practical issues, particularly in noisy settings like the clinical environment $[36,53]$. In a complex environment with multiple competing cues, the pairing of low intensity spatially and temporally coincident auditory and visual cues is likely to result in substantial improvements in the speed and accuracy of responses [59,60,62]. However, alarms have yet to be designed that take advantage of these known multisensory principles of human neural and perceptual performance. We advocate for design principles that take advantage of our knowledge in regards to how the human nervous system combines different sensory cues.

One additional element of the OR environment that should also be considered is background music, which is commonly present in the OR [63]. Such music can compete with existing task-relevant information. Indeed, multiple case reports presented in the Anesthesia Incident Reporting System (AIRS) in the newsletter of the Anesthesia Patient Safety Foundation (APSF) highlight that loud music interferes with safe patient care in the OR [64]. It is suggested that clinicians can ameliorate these effects through the use of "smart" OR music that adjusts volume down during critical patient care episodes $[63,65]$. For example, the Canary Box is a device that utilizes vital sign algorithms to mute music in times that require focus and quiet [66]. The lowered music volume during emergency periods serves as an alert in itself, as the acoustic environment has been automatically changed based on the clinical status of the patient. Collectively, this work illustrates that it is time for the experimental design of low intensity multisensory alarms that can dynamically change stimulus output depending on the current auditory and visual environment in the OR.

\section{Acoustic Features of Alarms-Tuning Stimulus Characteristics to Optimize Multisensory Benefit}

The ability to generate the most effective multisensory alarm also depends on the characteristics of the individual streams of sensory information, which have features embedded within them that must be considered when focusing on alarm design. For example, the auditory component of the alarm has several physical characteristics (e.g., volume, pitch, and timbre), each of which can be used to signal a meaningful physiological feature, as discussed previously. Recent work by McNeer et. al. shows that use of auditory icons, one novel option to be used as the auditory component, resulted in significantly better performance compared to standard alarms. An auditory icon is a sound that reflects the actual action to which its signal refers-for example, the lub-dub of a heartbeat. In this study, participants identified icon alarms 3 seconds quicker and $45 \%$ more accurately than standard alarms. Additionally, icon alarms were found to have lower perceived fatigue and task load [67]. These within-modality efforts to parse information may actively work against multisensory binding as the signals may be far from optimized for interactions that take advantage of the redundancies and additional information available from multisensory cues.

Focusing first on audible volume, we can return to the principle of inverse effectiveness [34,53] and the implications that it has for issues such as alarm fatigue. As we have seen, this principle 
illustrates that the largest gains in multisensory perception typically result from signals that are weakly effective when presented individually. Given this, we could imagine the development of an alarm where the effective volume could be lowered if the audible signal was efficiently coupled with a (weak) visual stimulus. This adjustment would lower the relative amplitude of the auditory alarm relative to the background noise, referred to as the signal-to-noise ratio (SNR) [18]. While in most circumstances a positive SNR (where the level of the signal is higher than the competing noise) is considered favorable, in naturalistic and multisensory settings there can be greater gains in signal detection under conditions of low or even negative SNR (in which the signal lies embedded within the noise). Currently, most clinical settings attempt to set an alarm at a higher volume than the overall background ICU noise to operate at a positive SNR. This, in turn, increases the overall noise in the ICU and can create a positive feedback loop of continually needing to increase the alarm volume. However, recent research shows that appropriate clinical performance can be maintained with alarms that $-11 \mathrm{~dB}$ below background noise as compared with $+4 \mathrm{~dB}$ above background noise (a typical real-world SNR) [68]. This research supports the principle of inverse effectiveness and should encourage further investigation.

In an effort to examine the impact of changes in SNR under multisensory circumstances and in a clinical scenario, ongoing work is examining performance on a common clinical duty of varying difficulty and under a range of alarm SNRs. Preliminary data suggest that clinician performance, measured by response time and accuracy on a clinically oriented detection task, can be preserved even under circumstances with a negative SNR, demonstrating that alarms do not need to be louder than background noise in order to maintain their efficacy $[3,36,37]$. This would allow the total sound/noise exposure to be decreased while maintaining high standards of clinical care.

In addition to features such as volume or SNR, other acoustical features of alarms include sound sharpness, fluctuation strength, consonance/dissonance, and roughness [69]. These features may play an important role in responsiveness to alarms and to their effective (mood related) content. For example, even novice Western music listeners have an emotional reaction to dissonance in music, as shown by the presentation of two excerpts from the cadenza in Ardi gli incensi from Donizetti's opera Lucia di Lammermoor where evoked emotions most commonly included sadness, madness, and fear of death [70-73]. Interestingly, the peak energy of the excerpts share the same harmonics with alarm characteristics signifying acute patient decompensation. Although these acoustic features likely allow alarms to be highly salient, it is seemingly maladaptive to allow alarms to possess acoustic features that consciously or unconsciously elicit negative emotions. Patient and practitioner outcomes may be improved if alarms possessed acoustic features that contributed to a more positively balanced sound environment while still serving their primary purpose.

The various acoustic features of alarms are barely mentioned in the applied acoustics literature, thus there exists opportunity embedded in the exploration of this space for improved alarm design [74]. Forging ahead to create international standards, in the absence of rigorous psychoacoustic studies to inform them, will (and already has) led to alarms that are difficult to learn [22,75]. For example, the utilization of only subtle rhythmic differences, in the face of static flat amplitude envelope (non-natural/non-percussive amplitude envelope), timbre, and pitch class (key) has resulted in a plethora of uninformative alarms [23,76-78]. Despite these growing observations regarding the richness of acoustic feature space and the potential opportunities for improved alarm design, international standards (e.g., IEC 60601-1-8) have been slow to change [79].

As should be clear from this section, it is necessary to more rigorously dissect the acoustical features of the auditory signal (e.g., SNR, pitch, timbre, rhythmicity, and amplitude envelope) in order to optimize alarm design from both a unisensory (i.e., auditory alone) and multisensory perspective $[78,80]$. Data from this line of research can also inform standards and safety in industries such as rail, aviation, and auto, which similarly face complex and noisy work environments [81]. 


\section{Visual Features of Alarms}

Supplementing work in the auditory domain, complementary to work in the visual domain can improve monitoring and safety to build off simple rules and expand to complex relationships that make use of multisensory principles to gain even greater benefits [82]. Visual information is typically not co-located with the patient, the clinician must utilize extensive eye and head movement to attend to the patient and monitor [83]. This constant movement is further complicated by evidence that shows the further away a stimulus is from fixation, the stronger the stimulus needs to be in order to be detected [84]. Furthermore, the loud, flashing visual signals alone, similar to unisensory auditory signals, are poorly informative because they do not indicate what the problem is, but merely signal the presence of a potential problem. If both visual and auditory stimuli are paired, as in a multisensory alarm, perhaps response time and overall environmental volume could decrease. Therefore, it is important to consider other situational factors that affect alarm response, and how these factors can be adapted to benefit patient care.

Similar to sound, visual feature space is rich and multidimensional, and represents fertile ground for the design of better alarms in both the visual and multisensory domains. Salient features in visual space that can and should be explored include brightness (analogous to auditory loudness or frequency/pitch), as well as color, hue, and saturation. A guiding principle from a multisensory alarm design perspective is that the visual signal should not only provide redundant information relative to the auditory alarm, but should also provide complementary information enabled by the non-overlapping nature of many aspects of auditory and visual signals [85].

\section{Interaction between Sensory Modalities and Cognitive Issues-Aspects of Vigilance}

Monitoring patient and medical equipment displays over extended periods of time requires a high level of vigilance and sustained attention [86]. The need for vigilance transcends the clinical setting, applying to many other fields such as transportation, process and quality control, and baggage inspection at airport security checkpoints [87-89]. The need for vigilance in the face of a high multisensory workload, whether salient or not, permeates practically every aspect of industry $[21,86]$.

In addition to addressing the sensory features by which alarms alert clinicians about various aspects of a patient's condition, another issue that alarm design needs to address is the impact of continuously streaming that sensory information. Alarms in the ICU sound frequently, and yet $85 \%$ to $99 \%$ of cases do not require clinical intervention [18]. Furthermore, as alarm frequency increases, clinicians experience habituation, which later results in missed alarms and delayed responses [17]. When alarms carry a positive predictive value of $\sim 27 \%$ or less, clinicians become desensitized to them [3]. In the presence of a majority of false or nonactionable alarms, clinicians change their behavior to reflect the perceived actionable percentage, that is, to respond $10 \%$ of the time if the alarm is deemed to be actionable $10 \%$ of the time [58,90]. While alarms are crucial to support clinician vigilance, excessive alarms lead to alarm fatigue that not only decreases the likelihood of response to valid alarms (i.e., "cry wolf" syndrome), but can also increase clinician stress and exhaustion [91-93]. In addition, the noise of multiple alarms, on top of the high noise levels in the clinical environment, can mask critical communication [56,94,95]. Perhaps most importantly, the noise from excessive alarms also adversely affects patients' sleep, cognition, psychological state, wound healing, and immune function [9]. Unfortunately, in many devices, even the quietest alarm is still loud, shrill, poorly informative, and unisensory. Since the majority of literature on alarm fatigue focuses on qualifiable aspects of fatigue as a function of alarm exposure, future research should focus on an operational and quantifiable assessment of alarm fatigue for the clinician and the potential patient adverse effects [58].

In addition to the workload of monitoring patients, the additional vigilance required can be highly stressful. Self-report indices have demonstrated task-induced negative mood shifts and increases in restlessness, subjective fatigue, sleepiness, and headaches [96]. Assuming "mindlessness" involves the withdrawal of effortful attention away from the task at hand, the workload and stress associated with patient tasks should decrease [97]. However, vigilance tasks with unisensory signals at a target 
rate of $2-5 \%$ show that stress and workload increase, as measured by the NASA Task Load Index and the Dundee Stress State Questionnaire $[86,96,98]$. Improving the signal-to-noise ratio and improved multisensory alarm design will address issues of attention, vigilance, and mindful allocation of cognitive resources.

\section{Patient Outcomes-Direct Effects of Alarms and Opportunities in the Multisensory Arena}

Applying multisensory principles to the clinical setting will benefit the clinician and the patient. There are demonstrable deleterious outcomes directly on the patients from excessive alarm exposure. The design of better alarms that include both the application of multisensory principles as well as greater attention to the sensory features of these alarms would have manifold benefits. In addition to reducing alarm fatigue, such an approach would decrease unnecessary auditory stimulation and the overall ambient noise level in a clinical environment. This would help to improve patient sleep duration and quality, thereby decreasing ICU delirium and potentially Post-ICU Syndrome (PICS), a relative to posttraumatic stress disorder (PTSD) [99,100]. In a recent Veterans Affairs (VA) study, patients newly diagnosed with PICS at one-year after hospital discharge occurred in nearly one in 12 ICU patients [101-104]. While civilian populations dominate the PTSD literature after critical illness, the incidence of PICS/PTSD anchored to critical illness was recently determined to be twice as common in veterans [101]. Although the contributions of excessive and/or poorly-designed alarms to ICU delirium and ICU-associated PTSD remain to be determined, it is highly likely that these represent significant contributions to these negative outcomes. Therefore, improving alarm design holds great promise for improving short- and long-term patient outcomes.

\section{Interference to Interoperability}

While there are multiple options of possible future routes, one inhibiting factor to a "smart" multisensory alarm is the issue of isolated solutions from single manufacturers and proprietary protocols. The tentativeness of integrating different manufacturers and devices leads to a missed opportunity of interoperability. Groups such as the US-American "MD PnP", Japanese "SCOT", and German "OR.NET" are working on comprehensive solutions for medical device interoperability based on open standards [105-111]. For example, MD PnP, a program based out of Massachusetts General Hospital, has created a Pulseless Electrical Activity (PEA) detection application [112]. This PEA detection application automatically reads data from several patient monitors, detects possible complications, and automatically displays the PEA treatment page of the Stanford Emergency Manual. By integrating various streams of information, the clinician is provided with the most comprehensive view of the patient and can make more informed decisions for treatment. These projects contribute to an increase in the quality of treatment and safety for both patient and provider. Unfortunately, this interoperable approach to design is not constant throughout the research community. While investigating future designs for multisensory alarms, it is important to consider the impact of interoperability across different manufacturers and devices.

\section{Roadmap of Multisensory Design}

As discussed previously, alarm design has been investigated from several points of view. As research has progressed, the prospective design of multisensory alarms has as well. The literature supports the notion that multisensory integration presents the opportunity to reduce alarm that is still able to be perceived at a lower threshold $[68,113]$. Evidence supports this perceptual additivity for the combination for olfactory and gustatory input, as well as auditory and visual input [114,115]. This is further supported by evidence that shows when a non-auditory stimulus is delivered at a sub-threshold level—so it is not perceived by the clinician—along with a near-threshold auditory stimulus, perception is maintained and the auditory environment is reduced [116].

With the literature supporting the benefits of multisensory integration, the physical placement of such a device is also important. For example, the anatomical location of a haptic device for a combined 
haptic and auditory alarm may alter results. It has been determined that placement of a vibrational device on the leg is beneficial due to the hygienic restrictions of wearing a device on the hand or wrist in a medical setting [116].

In adopting a multisensory model for patient alarm systems, both the academic researchers and industrial developers must cooperate and contribute to the design aspects. A projected roadmap of investigation includes research with a focus on developing a combination of unisensory streams which interact to provide the most beneficial effect in the medical alarm environment. Most recently, researchers investigated the benefit of a multisensory alarm compared to a conventional, unisensory alarm. The multisensory alarm consisted of a haptic actuator paired with an auditory stimulus. The results from this study show a positive trend toward participants' increased accuracy in identifying the variable's identity and point of change with the multisensory alarm compared to unisensory [117].

With regards to the potential limitations, one issue unique to the American market concerning the application of a multisensory design is the structure of research grants. Unlike countries such as the Netherlands and Canada, innovation grants delegated in America are industry-based. As a result, American academics are often restricted in their research because it is entirely dictated by industry demands. Therefore, a primary barrier on the road to production is the transition from the academic community to the industry developers and finally to the popular press. Furthermore, the progression from popular press to community adoption and integration into the hospital system poses challenges to any innovative designs. Fortunately, many new medical devices have begun to overcome such barriers. For example, a frequency-selective silencing device, which aims to filter alarm sounds from the ICU to reduce alarm fatigue for healthcare providers and reduce negative side effects for patients, has successfully transitioned from the academic community to the popular press forum CNN [118].

Other obstacles include considerations for alarm accuracy. It is common in an ICU environment with the constant buzz of patient alarms for healthcare professionals to silence or turn off monitors. This endangers patients as well as places healthcare professionals at legal risk. In a study aimed to decrease nuisance alarms and moderate alarm fatigue, researchers conducted an experiment to individualize patient alarms. By redefining the parameters for each alarm, nurses' responses to patient needs improved, and the nurses were less hindered by useless noise [13]. While alarm accuracy is a key factor in design, the ability of healthcare professionals to detect important alarms signals is equally as important. With regards to accuracy, the components to consider include durability, consistency, and simplicity or signal. Such aspects influence the overall setting of the ICU and consequently the ability of hospital staff to effectively attend to patients [119].

Finally, to design the most effective alarm system, a global standard must be established. The consistency of patient alarms between hospitals, states, and countries is crucial in managing the consequences of alarm fatigue and interpretability. This also eases the transition for healthcare professionals who transplant into a new hospital unit. By taking a top-down approach to designing medical technology, there is an opportunity to affect major change in patient outcome as well as physician accuracy [120].

\section{The Future of Multisensory Design}

Clinical environments, especially the ICU and OR, are high-consequence environments that require continuous divided and vigilant attention. The acoustic environment is densely congested with various alarms; however, the design of these critical alarms has not advanced to fully capitalize on our current knowledge of the benefits of multisensory integration. Continuing to ignore the possible interventions and advancement of alarm design through multisensory design, neuroscience of music perception, and music cognition is willfully myopic.

Alarms share various characteristics with musical structure, volume, and amplitude envelope. Despite technological advancements, medical devices fail to take full advantage of high-quality sound speakers. Current devices have been developed to address the inappropriate and invasive volume of alarms that contribute to poor communication in the clinical setting. For example, the 
Canary Box silences music in the OR at high risk times, and the Dynamic Alarm System for Hospitals (DASH) adjusts volume output proportional to the background environment $[66,121]$. Furthermore, CareTunes is a distinct attempt at addressing alarm fatigue in nurses. Through advanced integration of sonification, CareTunes allows nurses to receive alarms with a high level of information to continuously monitor their patients [122,123].

Additionally, amplitude envelope manipulation can create more aesthetically pleasing sounds with greater heterogeneity [23]. One possible change in alarms is the simple integration of a percussive envelope, in place of the standard flat envelope. This is more characteristic of naturally occurring sounds and could offer more information, higher learnability, and less annoyance. Alarm annoyance and poor learnability are problems that affect both clinicians and patients. This deleterious effect can result in future development of alarm fatigue in the clinician and PICS in the patient. Recent research shows increased perception and preference for the multisensory alarm over unisensory, auditory alarm [117]. The benefits of audio-visual multisensory integration are demonstrated in formal research, as well as daily life by the Cocktail Party Effect [36,37].

Should alarms prove to be a risk factor for developing PICS, as it is hypothesized, then there is a heightened urgency to improve alarm design. This concern is furthered by the notion that treatment for this form of delirium is not proven to be effective [124]. As a result, research and clinical practice need to be proactive. For example, since patients do not need to perceive audible medical alarms, wearable in-ear devices have been developed that filter-out specific frequencies associated with alarms. As a result, the patients can experience normal hearing without the negative consequences of aversive alarms. By globally decrease acoustic input, these in-ear devices may contribute to a decrease in PICS and ICU delirium $[125,126]$.

Given that alarm fatigue and PICS are widespread and poorly understood issues in medicine, multisensory integration with the goal of improving alarm design has become a critical issue in the field of alarm and multimodal design. These are just a few of the numerous opportunities to rethink and revamp the alarm for the benefit of clinicians, patients, and overall healthcare.

\section{Conclusions}

The concepts of multisensory integration and related neuroscience principles have rarely been applied to clinical settings. The utility of applying the concepts of multisensory integration to the clinical environment may ultimately lie in the increased ability to process complex information within an attentionally demanding setting, and in the decreased need for high intensity stimuli as primary alarm delimiters. There has been significant work showing the problems with alarm fatigue and a subsequent call-to-action to improve patient monitoring $[4,9,12,14,17]$. We believe that the neuroscience concepts articulated in this manuscript provide a powerful set of tools to design better alarms and patient monitoring environments for the clinician and patient. Clinicians are already required to integrate information across modalities; now is the time for alarms and patient monitors to adopt these neuroscience principles in an efficient, effective, and safe manner.

Author Contributions: Conceptualization, K.B., Madison Courtney and J.J.S.; Investigation, K.B. and M.C.; Project administration, J.J.S.; Visualization, J.J.S.; Writing—original draft, K.B. and M.C.; Writing—review \& editing, K.B., M.C., J.J.S., M.T.W. and S.H.B.M.

Funding: This research received no external funding.

Acknowledgments: The authors would like to thank Vanderbilt University Medical Center Department of Anesthesiology - especially Pratik Pandharipande and Matthew Weinger for granting non-clinical time for Joseph Schlesinger for this effort.

Conflicts of Interest: The authors declare no conflict of interest. 


\section{References}

1. Santangelo, V.; Fagioli, S.; Macaluso, E. The costs of monitoring simultaneously two sensory modalities decrease when dividing attention in space. Neuroimage 2010, 49, 2717-2727. [CrossRef] [PubMed]

2. Munoz, N.E.; Blumstein, D.T. Multisensory perception in uncertain environments. Behav. Ecol. 2012, 23, 457-462. [CrossRef]

3. Cvach, M. Monitor alarm fatigue: An integrative review. Biomed. Instrum. Technol. 2012, 46, $268-277$. [CrossRef] [PubMed]

4. Stevenson, R.A.; Schlesinger, J.J.; Wallace, M.T. Effects of divided attention and operating room noise on perception of pulse oximeter pitch changesa laboratory study. Anesthesiology 2013, 118, 376-381. [CrossRef] [PubMed]

5. Sendelbach, S.; Funk, M. Alarm fatigue: A patient safety concern. AACN Adv. Crit. Care 2013, 24, 378-386. [CrossRef]

6. Linkov, J. Collision-Avoidance Systems Are Changing the Look of Car Safety. Available online: https:// www.consumerreports.org/car-safety/collision-avoidance-systems-are-changing-the-look-of-car-safety/ (accessed on 29 November 2018).

7. Patterson, R. Guidelines for Auditory Warning Systems of Civil Aircraft; Civil Aviation Authority: London, UK, 1982.

8. Wise, J.A.; Hopkin, V.D.; Garland, D.J. Handbook of Aviation Human Factors; CRC Press: Boca Raton, FL, USA, 2016.

9. Choiniere, D.B. The effects of hospital noise. Nurs. Adm. Q. 2010, 34, 327-333. [CrossRef]

10. Xie, H.; Kang, J.; Mills, G.H. Clinical review: The impact of noise on patients' sleep and the effectiveness of noise reduction strategies in intensive care units. Crit. Care 2009, 13, 208. [CrossRef]

11. Kamdar, B.B.; Needham, D.M.; Collop, N.A. Sleep deprivation in critical illness: Its role in physical and psychological recovery. J. Intensiv. Care Med. 2012, 27, 97-111. [CrossRef]

12. Magnée, M.J.C.M.; de Gelder, B.; van Engeland, H.; Kemner, C. Multisensory integration and attention in autism spectrum disorder: Evidence from event-related potentials. PLoS ONE 2011, 6, e24196. [CrossRef]

13. Graham, K.C.; Cvach, M. Monitor alarm fatigue: Standardizing use of physiological monitors and decreasing nuisance alarms. Am. J. Crit. Care 2010, 19, 28-34. [CrossRef]

14. Schlesinger, J.J.; Stevenson, R.A.; Shotwell, M.S.; Wallace, M.T. Improving pulse oximetry pitch perception with multisensory perceptual training. Anesth. Analg. 2014, 118, 1249-1253. [CrossRef] [PubMed]

15. Commission, J. Medical device alarm safety in hospitals. Sentinel Event Alert 2013, 50, 1-3.

16. Occupational Safety and Health Administration-Employee Alarm Systems. Available online: https:// www.osha.gov/laws-regs/regulations/standardnumber/1910/1910.165 (accessed on 29 November 2018).

17. Kit, S. ECRI's Top 10 Health Technology Hazards for 2013. Health Devices 2013, 41, 342-365.

18. Logan, M.K. A Roundtable Discussion: Home Healthcare-Not A Hospital in the Home. Biomed. Instrum. Technol. 2013, 47, 10-15. [CrossRef] [PubMed]

19. Lewicki, M.S. Efficient coding of natural sounds. Nat. Neurosci. 2002, 5, 356-363. [CrossRef]

20. Low, H.C.; Silver, M.I.; Brown, B.J.; Leng, C.Y.; Blas, M.M.; Gravitt, P.E.; Woo, Y.L. Comparison of Hybribio GenoArray and Roche human papillomavirus (HPV) linear array for HPV genotyping in anal swab samples. J. Clin. Microbiol. 2015, 53, 550-556. [CrossRef]

21. Schlesinger, J. Pulse Oximetry: Perception, Pitch, Psychoacoustics, and Pedagogy. Anesth. Analg. 2016. [CrossRef]

22. Sanderson, P.M.; Wee, A.; Lacherez, P. Learnability and discriminability of melodic medical equipment alarms. Anaesthesia 2006, 61, 142-147. [CrossRef]

23. Schutz, M.; Stefanucci, J.K.; H Baum, S.; Roth, A. Name that percussive tune: Associative memory and amplitude envelope. Q. J. Exp. Psychol. 2017, 70, 1323-1343. [CrossRef]

24. Sharmila Sreetharan, J.S.; Michael, S. Designing Effective Auditory Interfaces: Exploring the Role of Amplitude Envelope. In Proceedings of the 15th International Conference on Music Perception and Cognition 10th Triennial Conference of the European Society for the Cognitive Sciences of Music, Graz, Austria, 23-28 July 2018.

25. Schellenberg, E.G.; Trehub, S.E. Good pitch memory is widespread. Psychol. Sci. 2003, 14, 262-266. [CrossRef]

26. Koelewijn, T.; Bronkhorst, A.; Theeuwes, J. Attention and the multiple stages of multisensory integration: A review of audiovisual studies. Acta Psychol. 2010, 134, 372-384. [CrossRef] [PubMed] 
27. Stanford, T.R.; Stein, B.E. Superadditivity in multisensory integration: Putting the computation in context. Neuroreport 2007, 18, 787-792. [CrossRef] [PubMed]

28. Berthoz, A.; Viaud-Delmon, I. Multisensory integration in spatial orientation. Curr. Opin. Neurobiol. 1999, 9 , 708-712. [CrossRef]

29. Lippert, M.; Logothetis, N.K.; Kayser, C. Improvement of visual contrast detection by a simultaneous sound. Brain Res. 2007, 1173, 102-109. [CrossRef] [PubMed]

30. Macaluso, E.; Driver, J. Spatial attention and crossmodal interactions between vision and touch. Neuropsychologia 2001, 39, 1304-1316. [CrossRef]

31. McDonald, J.J.; Teder-Sälejärvi, W.A.; Russo, F.D.; Hillyard, S.A. Neural substrates of perceptual enhancement by cross-modal spatial attention. J. Cogn. Neurosci. 2003, 15, 10-19. [CrossRef] [PubMed]

32. Nelson, W.T.; Hettinger, L.J.; Cunningham, J.A.; Brickman, B.J.; Haas, M.W.; McKinley, R.L. Effects of localized auditory information on visual target detection performance using a helmet-mounted display. Hum. Factors 1998, 40, 452-460. [CrossRef] [PubMed]

33. Senkowski, D.; Saint-Amour, D.; Höfle, M.; Foxe, J.J. Multisensory interactions in early evoked brain activity follow the principle of inverse effectiveness. Neuroimage 2011, 56, 2200-2208. [CrossRef] [PubMed]

34. Stevenson, R.A.; Fister, J.K.; Barnett, Z.P.; Nidiffer, A.R.; Wallace, M.T. Interactions between the spatial and temporal stimulus factors that influence multisensory integration in human performance. Exp. Brain Res. 2012, 219, 121-137. [CrossRef]

35. Stevenson, R.A.; James, T.W. Audiovisual integration in human superior temporal sulcus: Inverse effectiveness and the neural processing of speech and object recognition. Neuroimage 2009, 44, 1210-1223. [CrossRef]

36. Ross, L.A.; Saint-Amour, D.; Leavitt, V.M.; Javitt, D.C.; Foxe, J.J. Do you see what I am saying? Exploring visual enhancement of speech comprehension in noisy environments. Cereb. Cortex 2006, 17, 1147-1153. [CrossRef] [PubMed]

37. Senkowski, D.; Saint-Amour, D.; Gruber, T.; Foxe, J.J. Look who's talking: The deployment of visuo-spatial attention during multisensory speech processing under noisy environmental conditions. Neuroimage 2008, 43, 379-387. [CrossRef] [PubMed]

38. Alais, D.; Cass, J. Multisensory perceptual learning of temporal order: Audiovisual learning transfers to vision but not audition. PLoS ONE 2010, 5, e11283. [CrossRef] [PubMed]

39. Busse, L.; Roberts, K.C.; Crist, R.E.; Weissman, D.H.; Woldorff, M.G. The spread of attention across modalities and space in a multisensory object. Proc. Natl. Acad. Sci. USA 2005, 102, 18751-18756. [CrossRef] [PubMed]

40. Spence, C. Multisensory flavour perception. Curr. Biol. 2013, 23, R365-R369. [CrossRef] [PubMed]

41. Stein, B.E.; Meredith, M.A. The Merging of the Senses; MIT Press: Cambridge, MA, USA, 1993.

42. De Gelder, B.; Bertelson, P. Multisensory integration, perception and ecological validity. Trends Cogn. Sci. 2003, 7, 460-467. [CrossRef]

43. Diederich, A.; Colonius, H. Bimodal and trimodal multisensory enhancement: Effects of stimulus onset and intensity on reaction time. Percept. Psychophys. 2004, 66, 1388-1404. [CrossRef]

44. Ghazanfar, A.A.; Lemus, L. Multisensory integration: Vision boosts information through suppression in auditory cortex. Curr. Biol. 2010, 20, R22-R23. [CrossRef]

45. Green, A.M.; Angelaki, D.E. Multisensory integration: Resolving sensory ambiguities to build novel representations. Curr. Opin. Neurobiol. 2010, 20, 353-360. [CrossRef]

46. Hairston, W.D.; Burdette, J.H.; Flowers, D.L.; Wood, F.B.; Wallace, M.T. Altered temporal profile of visual-auditory multisensory interactions in dyslexia. Exp. Brain Res. 2005, 166, 474-480. [CrossRef]

47. King, A.J.; Calvert, G.A. Multisensory integration: Perceptual grouping by eye and ear. Curr. Biol. 2001, 11, R322-R325. [CrossRef]

48. Klemen, J.; Chambers, C.D. Current perspectives and methods in studying neural mechanisms of multisensory interactions. Neurosci. Biobehav. Rev. 2012, 36, 111-133. [CrossRef] [PubMed]

49. Kwakye, L.D.; Foss-Feig, J.H.; Cascio, C.J.; Stone, W.L.; Wallace, M.T. Altered auditory and multisensory temporal processing in autism spectrum disorders. Front. Integr. Neurosci. 2011, 4, 129. [CrossRef] [PubMed]

50. Lewkowicz, D.J.; Ghazanfar, A.A. The emergence of multisensory systems through perceptual narrowing. Trends Cogn. Sci. 2009, 13, 470-478. [CrossRef] [PubMed]

51. Meredith, M.A.; Nemitz, J.W.; Stein, B.E. Determinants of multisensory integration in superior colliculus neurons. I. Temporal factors. J. Neurosci. 1987, 7, 3215-3229. [CrossRef] [PubMed] 
52. Molholm, S.; Martinez, A.; Shpaner, M.; Foxe, J.J. Object-based attention is multisensory: Co-activation of an object's representations in ignored sensory modalities. Eur. J. Neurosci. 2007, 26, 499-509. [CrossRef]

53. Stevenson, R.A.; Bushmakin, M.; Kim, S.; Wallace, M.T.; Puce, A.; James, T.W. Inverse effectiveness and multisensory interactions in visual event-related potentials with audiovisual speech. Brain Topogr. 2012, 25, 308-326. [CrossRef]

54. Sperdin, H.F.; Cappe, C.; Foxe, J.J.; Murray, M.M. Early, low-level auditory-somatosensory multisensory interactions impact reaction time speed. Front. Integr. Neurosci. 2009, 3, 2. [CrossRef]

55. Bholat, O.S.; Haluck, R.S.; Murray, W.B.; Gorman, P.J.; Krummel, T.M. Tactile feedback is present during minimally invasive surgery. J. Am. Coll. Surg. 1999, 189, 349-355. [CrossRef]

56. Weinger, M.B.; Reddy, S.B.; Slagle, J.M. Multiple measures of anesthesia workload during teaching and nonteaching cases. Anesth. Analg. 2004, 98, 1419-1425. [CrossRef]

57. Biebuyck, J.F.; Weinger, M.B.; Englund, C.E. Ergonomic and human factors affecting anesthetic vigilance and monitoring performance in the operating room environment. Anesthesiology 1990, 73, 995-1021. [CrossRef]

58. Paine, C.W.; Goel, V.V.; Ely, E.; Stave, C.D.; Stemler, S.; Zander, M.; Bonafide, C.P. Systematic review of physiologic monitor alarm characteristics and pragmatic interventions to reduce alarm frequency. J. Hosp. Med. 2016, 11, 136-144. [CrossRef] [PubMed]

59. Powers, A.R.; Hevey, M.A.; Wallace, M.T. Neural correlates of multisensory perceptual learning. J. Neurosci. 2012, 32, 6263-6274. [CrossRef] [PubMed]

60. Powers, A.R.; Hillock, A.R.; Wallace, M.T. Perceptual training narrows the temporal window of multisensory binding. J. Neurosci. 2009, 29, 12265-12274. [CrossRef] [PubMed]

61. Stevenson, R.A.; Wilson, M.M.; Powers, A.R.; Wallace, M.T. The effects of visual training on multisensory temporal processing. Exp. Brain Res. 2013, 225, 479-489. [CrossRef] [PubMed]

62. Clock, A.E.; Salvi, R.J.; Saunders, S.S.; Powers, N.L. Neural correlates of temporal integration in the cochlear nucleus of the chinchilla. Hear. Res. 1993, 71, 37-50. [CrossRef]

63. JJ, S.; Stevenson, R.A.; Wallace, M.T. In response: Smart operating room music. Anesth. Analg. 2015, 121, 836.

64. Sutherland, A.D.; Faragher, I.G.; Frizelle, F.A. Intradermal injection of methylene blue for the treatment of refractory pruritus ani. Colorectal Dis. 2009, 11, 282-287. [CrossRef]

65. MacDonald, A. Smart operating room music. Anesth. Analg. 2015, 121, 836. [CrossRef]

66. MacDonald, A.; Schlesinger, J. Canary in an Operating Room: Integrated Operating Room Music. Available online: https:/ / www.hfes-europe.org/wp-content/uploads/2017/10/MacDonald2017.pdf (accessed on 29 November 2018).

67. McNeer, R.R.; Horn, D.B.; Bennett, C.L.; Edworthy, J.R.; Dudaryk, R. Auditory Icon Alarms Are More Accurately and Quickly Identified than Current Standard Melodic Alarms in a Simulated Clinical Setting. Anesthesiology 2018, 129, 58-66. [CrossRef]

68. Schlesinger, J.J.; Baum Miller, S.H.; Nash, K.; Bruce, M.; Ashmead, D.; Shotwell, M.S.; Edworthy, J.R.; Wallace, M.T.; Weinger, M.B. Acoustic features of auditory medical alarms-An experimental study of alarm volume. J. Acoust. Soc. Am. 2018, 143, 3688-3697. [CrossRef] [PubMed]

69. Irwin, A.; Hall, D.A.; Peters, A.; Plack, C.J. Listening to urban soundscapes: Physiological validity of perceptual dimensions. Psychophysiology 2011, 48, 258-268. [CrossRef] [PubMed]

70. Koelsch, S.; Kasper, E.; Sammler, D.; Schulze, K.; Gunter, T.; Friederici, A.D. Music, language and meaning: Brain signatures of semantic processing. Nat. Neurosci. 2004, 7, 302-307. [CrossRef] [PubMed]

71. Peretz, I.; Champod, A.S.; Hyde, K. Varieties of musical disorders: The Montreal Battery of Evaluation of Amusia. Ann. N. Y. Acad. Sci. 2003, 999, 58-75. [CrossRef]

72. Patil, K.; Pressnitzer, D.; Shamma, S.; Elhilali, M. Music in our ears: The biological bases of musical timbre perception. PLoS Comput. Biol. 2012, 8, e1002759. [CrossRef]

73. Siegwart-Zesiger, H.M.; Scherer, K.R. Acoustic concomitants of emotional expression in operatic singing: The case of Lucia in Ardi gli incensi. J. Voice 1995, 9, 249-260. [CrossRef]

74. Lemaitre, G.; Houix, O.; Misdariis, N.; Susini, P. Listener expertise and sound identification influence the categorization of environmental sounds. J. Exp. Psychol. Appl. 2010, 16, 16-32. [CrossRef]

75. Edworthy, J.R.; Edworthy, J.D. Audible medical alarms. Anaesthesia 2015, 70, 1215. [CrossRef]

76. Block, F.E. For if the trumpet give an uncertain sound, who shall prepare himself to the battle? (I Corinthians 14: 8, KJV). Anesth. Analg. 2008, 106, 357-359. [CrossRef] 
77. Block, F.E.; Rouse, J.D.; Hakala, M.; Thompson, C.L. A proposed new set of alarm sounds which satisfy standards and rationale to encode source information. J. Clin. Monit. Comput. 2000, 16, 541-546. [CrossRef]

78. Vallet, G.T.; Shore, D.I.; Schutz, M. Exploring the role of the amplitude envelope in duration estimation. Perception 2014, 43, 616-630. [CrossRef] [PubMed]

79. ICU Delirium and Cognitive Impairment Study Group. Available online: https://slideplayer.com/slide/ 1719671/ (accessed on 29 November 2018).

80. Manning, F.C.; Schutz, M. Trained to keep a beat: Movement-related enhancements to timing perception in percussionists and non-percussionists. Psychol. Res. 2016, 80, 532-542. [CrossRef] [PubMed]

81. Blike, G.T. The challenges of human engineering research. J. Clin. Monit. Comput. 1999, 15, 413-415. [CrossRef]

82. Sanderson, P.M.; Watson, M.O.; Russell, W.J. Advanced patient monitoring displays: Tools for continuous informing. Anesth. Analg. 2005, 101, 161-168. [CrossRef] [PubMed]

83. Sanderson, P. The multimodal world of medical monitoring displays. Appl. Ergon. 2006, 37, 501-512. [CrossRef] [PubMed]

84. Shive, J.; Schlesinger, J.J.; Jester, J.K. Peripheral Colour Contrast Sensitivity Under Perceptual Load. In Proceedings of the Human Factors and Ergonomics in Health Care, Washington, DC, USA, 27-31 July 2016.

85. Perry, N.C.; Stevens, C.J.; Wiggins, M.W.; Howell, C.E. Cough once for danger: Icons versus abstract warnings as informative alerts in civil aviation. Hum. Factors 2007, 49, 1061-1071. [CrossRef]

86. Grier, R.A.; Warm, J.S.; Dember, W.N.; Matthews, G.; Galinsky, T.L.; Szalma, J.L.; Parasuraman, R. The vigilance decrement reflects limitations in effortful attention, not mindlessness. Hum. Factors 2003, 45, 349-359. [CrossRef] [PubMed]

87. Finomore, V.S., Jr.; Shaw, T.H.; Warm, J.S.; Matthews, G.; Boles, D.B. Viewing the workload of vigilance through the lenses of the NASA-TLX and the MRQ. Hum. Factors 2013, 55, 1044-1063. [CrossRef]

88. Funke, G.J.; Warm, J.S.; Baldwin, C.L.; Garcia, A.; Funke, M.E.; Dillard, M.B.; Finomore, V.S., Jr.; Matthews, G.; Greenlee, E.T. The independence and interdependence of coacting observers in regard to performance efficiency, workload, and stress in a vigilance task. Hum. Factors 2016, 58, 915-926. [CrossRef] [PubMed]

89. Hancock, P.A. A dynamic model of stress and sustained attention. Hum. Factors 1989, 31, 519-537. [CrossRef] [PubMed]

90. Karnik, A.; Bonafide, C.P. A framework for reducing alarm fatigue on pediatric inpatient units. Hosp. Pediatr. 2015, 5, 160-163. [CrossRef] [PubMed]

91. Weinger, M.B. Vigilance, boredom, and sleepiness. J. Clin. Monit. Comput. 1999, 15, 549-552. [CrossRef]

92. Weinger, M.B.; Ancoli-Israel, S. Sleep deprivation and clinical performance. JAMA 2002, $287,955-957$. [CrossRef] [PubMed]

93. Weinger, M.B.; Gaba, D.M. Human factors engineering in patient safety. Anesthesiology 2014, 120, 801-806. [CrossRef] [PubMed]

94. Weinger, M.B.; Pantiskas, C.; Wiklund, M.E.; Carstensen, P. Incorporating human factors into the design of medical devices. JAMA 1998, 280, 1484. [CrossRef] [PubMed]

95. Weinger, M.B.; Slagle, J. Human Factors Research in Anesthesia Patient Safety. Available online: https: / /academic.oup.com/jamia/article/9/Supplement_6/S58/703195 (accessed on 29 November 2018).

96. Szalma, J.L.; Hancock, P.A.; Dember, W.N.; Warm, J.S. Training for vigilance: The effect of knowledge of results format and dispositional optimism and pessimism on performance and stress. Br. J. Psychol. 2006, 97, 115-135. [CrossRef] [PubMed]

97. Manly, T.; Robertson, I.H.; Galloway, M.; Hawkins, K. The absent mind: Further investigations of sustained attention to response. Neuropsychologia 1999, 37, 661-670. [CrossRef]

98. Hitchcock, E.M.; Dember, W.N.; Warm, J.S.; Moroney, B.W.; See, J.E. Effects of cueing and knowledge of results on workload and boredom in sustained attention. Hum. Factors 1999, 41, 365-372. [CrossRef] [PubMed]

99. Ely, E.W.; Siegel, M.D.; Inouye, S.K. Delirium in the Intensive Care Unit: An Under-Recognized Syndrome of Organ Dysfunction; Thieme Medical Publishers, Inc.: New York, NY, USA, 2001; Volume 22, pp. 115-126.

100. Jackson, J.C.; Pandharipande, P.P.; Girard, T.D.; Brummel, N.E.; Thompson, J.L.; Hughes, C.G.; Pun, B.T.; Vasilevskis, E.E.; Morandi, A.; Shintani, A.K.; et al. Depression, post-traumatic stress disorder, and functional 
disability in survivors of critical illness in the BRAIN-ICU study: A longitudinal cohort study. Lancet Respir. Med. 2014, 2, 369-379. [CrossRef]

101. Patel, M.B.; Jackson, J.C.; Morandi, A.; Girard, T.D.; Hughes, C.G.; Thompson, J.L.; Kiehl, A.L.; Elstad, M.R.; Wasserstein, M.L.; Goodman, R.B. Incidence and risk factors for intensive care unit-related post-traumatic stress disorder in veterans and civilians. Am. J. Respir. Crit. Care Med. 2016, 193, 1373-1381. [CrossRef]

102. American Psychiatric, A. Diagnostic and Statistical Manual of Mental Disorders (DSM- $\left.5^{\circledR}\right)$; American Psychiatric Association: Washington, DC, USA, 2013.

103. Brewin, C.R. Systematic review of screening instruments for adults at risk of PTSD. J. Trauma. Stress 2005, 18, 53-62. [CrossRef] [PubMed]

104. Burdick, K.; Courtney, M.C.; Schlesinger, J.J. Post-Intensive Care Syndrome (PICS): Behavioral Therapies. In Lessons from the ICU; Springer: Berlin, Germany, 2019.

105. Goldman, J.; Jackson, J.; Whitehead, S.; Rausch, T.; Weininger, S. The Medical Device "Plug-and-Play" (MD PnP) Interoperability Program. Computer 2006, 39, 30-31.

106. Arney, D.; Plourde, J.; Goldman, J.M. OpenICE medical device interoperability platform overview and requirement analysis. Biomed. Tech. 2018, 63, 39-47. [CrossRef] [PubMed]

107. Celdrán, A.H.; Clemente, F.J.G.; Weimer, J.; Lee, I. ICE++: Improving Security, QoS, and High Availability of Medical Cyber-Physical Systems through Mobile Edge Computing. In Proceedings of the 2018 IEEE 20th International Conference on e-Health Networking, Applications and Services (Healthcom), Ostrava, Czech Republic, 17-20 September 2018; pp. 1-8.

108. Okamoto, J.; Masamune, K.; Iseki, H.; Muragaki, Y. Development concepts of a smart cyber operating theater (SCOT) using ORiN technology. Biomed. Tech. 2018, 63, 31-37. [CrossRef] [PubMed]

109. Okamoto, J.; Masamune, K.; Iseki, H.; Muragaki, Y. Development of a next-generation operating room "Smart Cyber Operating Theater (SCOT)"-development concept and project summay. In Proceedings of the CARS, Barcelona, Spain, 24-27 June 2015; pp. 156-158.

110. Kasparick, M.; Schmitz, M.; Andersen, B.; Rockstroh, M.; Franke, S.; Schlichting, S.; Golatowski, F.; Timmermann, D. OR. NET: A service-oriented architecture for safe and dynamic medical device interoperability. Biomed. Tech. 2018, 63, 11-30. [CrossRef] [PubMed]

111. Rockstroh, M.; Franke, S.; Hofer, M.; Will, A.; Kasparick, M.; Andersen, B.; Neumuth, T. OR. NET: Multi-perspective qualitative evaluation of an integrated operating room based on IEEE 11073 SDC. Int. J. Comput. Assist. Radiol. Surg. 2017, 12, 1461-1469. [CrossRef]

112. Goldman, J.; Arney, D.; Peterson, J.; Alonso, D.; Feinberg, M.; Weininger, S.; Dain, S.; Engel, T.; Rausch, T. Integrated Clinical Environments (ICE) to Improve Safety and Enable Rapid Innovation Demonstration: Safety System to Automatically Detect PEA and Display a Cognitive Aid. Available online: https://www.researchgate.net/publication/293482785_Integrated_Clinical_Environments_ICE_ to_Improve_Safety_and_Enable_Rapid_Innovation_Demonstration_Safety_System_to_Automatically_ Detect_PEA_and_Display_a_Cognitive_Aid (accessed on 29 November 2018).

113. Visell, Y.; Giordano, B.L.; Millet, G.; Cooperstock, J.R. Vibration influences haptic perception of surface compliance during walking. PLoS ONE 2011, 6, e17697. [CrossRef]

114. Diamond, J.; Breslin, P.A.; Doolittle, N.; Nagata, H.; Dalton, P. Flavor processing: Perceptual and cognitive factors in multi-modal integration. Chem. Senses 2005, 30, i232-i233. [CrossRef] [PubMed]

115. Noesselt, T.; Tyll, S.; Boehler, C.N.; Budinger, E.; Heinze, H.-J.; Driver, J. Sound-induced enhancement of low-intensity vision: Multisensory influences on human sensory-specific cortices and thalamic bodies relate to perceptual enhancement of visual detection sensitivity. J. Neurosci. 2010, 30, 13609-13623. [CrossRef]

116. Alirezaee, P.; Girgis, R.; Kim, T.; Schlesinger, J.J.; Cooperstock, J.R. Did you Feel that? Developing Novel Multimodal Alarms for High Consequence Clinical Environments; Georgia Institute of Technology: Atlanta, GA, USA, 2017.

117. Burdick, K.; Jorgensen, S.K.; Holmberg, M.O.; Kultgen, S.P.; Combs, T.N.; Schlesinger, J.J. Benefits of sonification and haptic displays with physiologic variables to improve patient safety. In Proceedings of the Acoustical Society of America, Victoria, BC, Canada, 8-10 November 2018.

118. Nedelman, M. Solving the Problem of Sleep in Hospitals. Cable News Network. Available online: https:/ / www. cnn.com/2017/07/10/health/hospital-sleep-noisy-alarms-study/index.html (accessed on 7 October 2017). 
119. Edworthy, J.R.; Schlesinger, J.J.; McNeer, R.R.; Kristensen, M.S.; Bennett, C.L. Classifying alarms: Seeking durability, credibility, consistency, and simplicity. Biomed. Instrum. Technol. 2017, 51, 50-57. [CrossRef] [PubMed]

120. Edworthy, J.; McNeer, R.; Bennett, C.; Dudaryk, R.; McDougall, S.; Schlesinger, J.; Bolton, M.; Reed Edworthy, J.; Özcan Vieira, E.; Boyd, A. Getting Alarm Sounds into a Global Standard: A Cases Study with Reflections. Available online: https:/ / pearl.plymouth.ac.uk/bitstream/handle/10026.1/11274/ Edworthy\%20EiD\%20revision\%20copy.pdf?sequence=1 (accessed on 29 November 2018).

121. Greer, J.M.; Burdick, K.J.; Chowdhury, A.R.; Schlesinger, J.J. Dynamic Alarm Systems for Hospitals (D.A.S.H.). Ergon. Des. 2018, 26, 14-19. [CrossRef]

122. Bogers, K. Care Tunes: Music as a Nurses' Monitoring Tool. 2018. Available online: https:/ /delftdesignlabs. org/criticalalarmslab/ (accessed on 29 November 2018).

123. Bogers, K.; Schlesinger, J.J. Care Tunes: A Musical Sonification for Critical Care. 2018. Available online: https:/ / www.ddw.nl/ (accessed on 29 November 2018).

124. Girard, T.D.; Exline, M.C.; Carson, S.S.; Hough, C.L.; Rock, P.; Gong, M.N.; Douglas, I.S.; Malhotra, A.; Owens, R.L.; Feinstein, D.J.; et al. Haloperidol and Ziprasidone for Treatment of Delirium in Critical Illness. N. Engl. J. Med. 2018, 379, 2506-2516. [CrossRef]

125. Brown, A.D.; Beemer, B.T.; Greene, N.T.; Argo Iv, T.; Meegan, G.D.; Tollin, D.J. Effects of active and passive hearing protection devices on sound source localization, speech recognition, and tone detection. PLOS ONE 2015, 10, e0136568. [CrossRef]

126. Schlesinger, J.J.; Reynolds, E.; Sweyer, B.; Pradham, A. Frequency-Selective Silencing Device for Digital Filtering of Audible Medical Alarm Sounds to Enhance ICU Patient Recovery; Georgia Institute of Technology: Atlanta, GA, USA, 2017.

(C) 2019 by the authors. Licensee MDPI, Basel, Switzerland. This article is an open access article distributed under the terms and conditions of the Creative Commons Attribution (CC BY) license (http:/ / creativecommons.org/licenses/by/4.0/). 